\title{
Demand for Cervical Cancer Screening in Tigray Region of Ethiopia in 2018: A Community-Based Cross-Sectional Study
}

This article was published in the following Dove Press journal: International Journal of Women's Health

\author{
Gerezgiher Buruh Abera (D) \\ Solomon Mekonen Abebe ${ }^{2}$ \\ Abebaw Gebeyehu Werku \\ 'School of Nursing, College of Health \\ Sciences, Mekelle University, Tigray, \\ Ethiopia; ${ }^{2}$ Institute of Public Health, \\ College of Medicine and Health Sciences, \\ University of Gondar, Amhara, Ethiopia; \\ ${ }^{3}$ Head of Amhara Regional Health \\ Bureau, Amhara, Ethiopia
}

Correspondence: Gerezgiher Buruh Abera

Tel +25l 9l-090-3186

Email gbamsc2002@gmail.com
Background: Cervical cancer is a public health concern worldwide, and is increasing in developing countries. Despite the efforts of governments, demand for cervical cancer screening is low and not well studied. As such, this study was done to figure out the demand for cervical cancer screening in Tigray regional state.

Methods: A cross-sectional study design was conducted, and 1,010 participants were recruited using simple random sampling. Data were collected using an intervieweradministered questionnaire, and analysis was done using multilevel logistic regression.

Results: A total of 1,000 women were included in the final analysis. The mean age of participants was $32.57 \pm 8.56$ years. Those demandeing cervical cancer screening numbered $480(48 \%)$. Intraclass correlation indicated that $18.9 \%$ of the total variance in demand was attributable to differences across the cluster districts $(p 0.0001)$. Predictors of demand for cervical cancer screening were age 31-40 years (AOR 2.33, 95\% CI 0.42-3.83) and 41-45 years (AOR 3.02, 95\% CI 1.64-5.55), tertiary education (AOR 2.81, 95\% CI 1.43-5.51), history of sexually transmitted disease (AOR 1.71, 95\% CI 1.05-2.79), being knowledgeable about cervical cancer, (AOR 9.21, 95\% CI 5.79-14.65), and having a positive attitude toward cervical cancer screening (AOR 8.32, 95\% CI 5.53-12.51). Among community level variables, community awareness of cervical cancer and population:health institution ratio were factors associated with demand.

Conclusion: Demand for cervical cancer screening is low compared to the government's plan for 2020. Health professionals and leaders need to focus on communit- level demand creation for cervical cancer screening by planning health-promotion strategies.

Keywords: adult women, cervical cancer screening, demand multilevel

\section{Introduction}

Cervical cancer is a public health concern worldwide, particularly in sub-Saharan Africa. Studies done in six countries have shown that the overall rate of cervical precancer lesions is approximately $10.1 \%{ }^{1}$ In Colombia, cervical cancer mortality declined rapidly from $27.2 \%$ in 1998 to $12.5 \%$ in $2013 .{ }^{2}$ A study done in Burkina Faso showed that the precancer-lesion rate was $8.9 \%$ and only $65.9 \%$ of women testing positive received cryotherapy, due to difficulties in tracking referred patients, shortage of supplies, and prohibitive user fees. ${ }^{3}$ The mortality pattern of cervical cancer is higher in old than young women and lower among those who have tertiary education. ${ }^{2}$ Such risk factors as early sexual debut and multiple sexual partners are important predictors of cervical cancer. ${ }^{4}$ 
"Demand" in this context is the expression of felt need from individuals perceiving a variation from normal health. Demand for cervical cancer screening incorporates willingness, plans for, and practice of screening. The demand of women for cervical cancer screening was measured in terms of willingness, plans to get screened within the next 6 months, and/or cervical cancer-screening practice. ${ }^{5}$ Demand for cervical cancer screening in developing countries has been found to be low. Interest of screening has been shown to be $11 \%$ in Kenya, 3.3\% in Nigeria, and $63 \%$ in Uganda. ${ }^{5-7}$ However, other research has shown up to $87.3 \%$ of participants have at least one cervical cancer screening in their lifetime. ${ }^{8}$

The difference in demand for cervical cancer screening is rising not only between countries, but also among geographical regions within a country. A null model in a study revealed that the amount of variation attributable to neighborhoods was $5.6 \%-7.3 \%{ }^{8}{ }^{89}$ Low demand for cervical cancer screening is related to low awareness of cervical cancer. The proportion of women with knowledge of cervical cancer is $32.3 \%$ in Nigeria and $37.4 \%$ in Gambia. ${ }^{10,11}$ Major sources of information about cervical cancer screening are health facilities $(31.3 \%)$ and friends $(30.9 \%),{ }^{12}$ though $34.2 \%$ of participants in other research knew about cervical cancer, but only $24.8 \%$ accepted the test. ${ }^{5,13}$ Self-perception of health status is also related to demand for cervical cancer screening. ${ }^{14,15}$

As shown in different studies, barriers to cervical cancer screening include socioeconomic status, education, ethnicity, geography, and fear or embarrassment. ${ }^{16}$ Other variables associated with acceptance of screening are sources of information, awareness of the test, preventability of the disease, employment, and living in rural areas. ${ }^{5,8,13,17,18}$ The level of acculturation and experience of sexual intercourse are also predictors of cervical cancer-screening behavior in Chinese women. ${ }^{15}$ The most common reasons given for not getting screened were lack of awareness, no need for it, and fear of a bad result. ${ }^{12}$ The most common attributable risk was being a male care provider, with values ranging from $16.8 \%$ in the Middle East and North Africa to $27.4 \%$ in East Asia and the Pacific. ${ }^{19}$

The Ethiopian Ministry of Health is striving to improvecervical cancer-screening demand. Ethiopia introduced the visual inspection with acetic acid (VIA) screening approach for a precancerous lesion in 2005. It is run by trained professionals as an essential health service. However, in 2018 only $2 \%$ of health institutions were providing cervical cancer screening in Ethiopia, and service utilization by eligible women remains low $(0.8 \%){ }^{20}$ Besides, there has been no study done on demand for cervical cancer screening in the study area. Therefore, this study focused on assessment of the demand of adult women for cervical cancer screening using the VIA method in the Tigray region. It also provides information about predictors of demand for cervical cancer screening.

\section{Methods}

\section{Study Area}

The study was conducted in Tigray region, which is located in northern Ethiopia and covers $53,638 \mathrm{~km}^{2}$. The region is divided administratively into seven zones and 52 districts (woredas, an administrative division of Ethiopia, managed by local government). Based on the federal population projection of 2014-2017, there are about $5,247,005$ populations in Tigray region, of which $2,516,003$ are female. ${ }^{21}$ Using the conversion factor of $23.5 \%$, about 591,261 are reproductive-age women. Thirty towns with cervical cancer screening available were considered for the study area in the region.

\section{Study Design and Period}

A community-based cross-sectional study design was conducted from January to April 2019.

\section{Source Population}

All sexually active adult women aged $20-60$ years who had lived in the study area for at least 6 months were included in this study. Those who had a history of hysterectomy were excluded.

\section{Sample Size and Sampling Technique}

The sample size was calculated with the assumption of a confidence level of $95 \%$ and proportions of $27 \%, 42 \%$, $62.7 \%$, and $56 \%$ from different studies considering the respective marginal error. ${ }^{22,23,24}$ By taking the proportion that gives the maximum sample size and assuming a $20 \%$ nonresponse rate, the total sample size was 1,010. Recruitment of participants was done using simple random sampling based on a list of eligible women prepared by a health-extension worker.

\section{Data-Collection Methods}

Data were collected by trained health professionals and health-extension workers in the selected districts. 
Participants were approached at their homes and asked to participate after being given basic information about the aim of the study. After they agreed to participate, an interviewer-administered questionnaire was used to collect data. The questionnaire was developed by reviewing different studies and had been tested on a similar community that was not included in the study. It comprises components of demographic, reproductive, and cervical cancerrelated variables.

\section{Study Variables Outcome Variable}

The outcome variable was women's demand for cervical cancer screening, defined as intent to get screened for cervical cancer (including willingness, plans, and undertaking screening), which was measured when a woman responded positively at least one of three questions: 1) "Do you have an interest in cervical cancer screening?"; 2) "Do you plan to get screened within the next 6 months?"; and 3) "Have you ever been screened for cervical cancer?" Respondes of "yes" for at least one of the three questions was considered as demand for cervical cancer screening.

\section{Explanatory Variables}

We used individual-level and community-level data. Individual-level variables were age, ethnicity, marital status, religion, education, occupation, number of sexual partners, use of modern contraceptives, number of children, abortion, age at first sexual encounter, sexually transmitted infection (STI), drug use for chronic disease, smoking, alcohol use, and knowledge of and attitude toward cervical cancer.

\section{Knowledge}

Nineteen items were used to assess knowledge and classified under four categories: information about cervical cancer (one item), types of signs and symptoms (six items), risk factors (eight items), and prevention methods (four items). Respondents were categorized as knowledgeable if they scored $>50 \%$ and regarded as less knowledgeable otherwise. ${ }^{11}$ Attitudes of participants toward cervical cancer screening were measured using six items asking about the respondents' degree of agreement with six-point Likert scales, scored from 0 (strongly disagree) to 5 (strongly agree). Attitudes were categorized as positive if they scored $>60 \%$ and less positive otherwise. ${ }^{11}$ Active or passive smoking was measured with yes/no questions, regardless of frequency and number of cigarettes. Alcohol consumption was considered any amount of alcohol, including traditional drinks like tela and arekie, and was measured in terms of frequency as always, sometimes, and never.

Community-level variables were nonaggregate and aggregate. Nonaggregate variables included type of residence and percentage of literacy (based on integrated functional adult education from an unpublished report in the regional education department). Aggregate variables included average family size, mean awareness score on cervical cancer, ratio of population to healthextension workers, ratio of health professionals involved in cervical cancer screening to population per thousand, and ratio of population per health institution in each district. Individual-level variables were used to develop some of the aggregate community-level explanatory variables. Mean family size was derived from the individuallevel variable using the Stata command "tabstat Family Size, stats (mean, n, sum) by (Cluster)". The average community-awareness score was also derived from the individual average score using the Stata command "tab Cluster, sum (Community Awareness)". Other community-level variables were developed based on Ethiopian health-policy guidelines. ${ }^{25-27}$

\section{Data Analysis}

In this research, we used data on individuallevel and community-level variables. Multilevel logistic regression was used to analyze these data. Crude ORs with $95 \%$ CIs were tested using Pearson's $\chi^{2}$, and variables with $p<0.05$ in the cross-tabulation were considered for multilevel multivariate logistic regression analysis.

\section{Model Building}

With the "xtmelogit" command, models I, II, and III were fitted using Stata version 14.0. The null model (model I) was fitted to see whether an intraclass correlation were $>5 \%$ or not for the determination of multilevel analysis. To inspect the influence of individual-level (level one) variables on the outcome variable, model II was fitted. Finally, model III was done using both level one and two explanatory variables to evaluate the adjusted effect size of the predictors on the outcome variable. To check differences in demand among the clusters, proportional change in variance was calculated in the two last models compared with the null model. Differences among models was assessed using the $\chi^{2}$ likelihood ratio, and $p<0.05$ was taken as statistically significant. 


\section{Ethical Issues}

This study was conducted in accordance with the Declaration of Helsinki. Ethical approval was received from the institutional review board of the University of Gondar (registration OIV/P/RCS/05/308/2017). Support letters were also taken from the regional health bureau to each district health office before data collection. Participants were informed about data collection, voluntary participation, the right of withdrawal, and privacy and confidentiality of their information. Finally, informed written consent was obtained before data collection.

\section{Results}

\section{Demographic Characteristics}

Of 1,010 participants, 1,000 (99\%) women were included in the final analysis. The mean age of participants was 32.57 \pm 8.56 years. Of the total, $501(50.1 \%)$ were in the age-range 31-40 years. Secondary and tertiary education wer more common among those who had demand for cervical screening: 197 (57.3\%) and 83 (62.4\%), respectively (Table 1).

\section{Reproductive Health}

Of the respondents, 554 (55.40\%) used contraceptives, 168 $(16.8 \%)$ had had five or more pregnancies, $120(12 \%)$ had had five or more children, and 178 (17.8\%)had had at least one abortion. Among those who had a history of abortion, $104(58.4 \%)$ had demand for cervical cancer screening, while $74(41.6 \%)$ had no demand. Among contraceptive users, 285 (51.4\%) showed demand and 269 (48.6\%) no demand (Table 2).

\section{Risk Factors of Cervical Cancer}

Age at first sexual contact for the participants was 7-31 years, with mean age of $17.55 \pm 3.19$ years. Of the participants, about $867(86.7 \%)$ had had their first sexual contact aged $\leq 20$ years, and $412(41.20 \%)$ had had at least two sexual partners in their lifetime. Seveny (7\%) were smokers, $69(6.9 \%)$ frequent alcohol users, and $83(8.3 \%)$ corticosteroid users. Regarding disease history, 177 $(17.7 \%)$ had experienced signs and symptoms of an STI, of which $110(62.15 \%)$ had demanded cervical cancer screening, while 67 (37.8\%) had not (Table 3).

\section{Knowledge and Attitudes of Participants on Cervical Cancer}

Among the participants, 470 (47\%) women had heard about cervical cancer, of which $298(63.4 \%)$ had heard about it from media and $133(28.2 \%)$ from health professionals. Only

Table I Bivariate Analysis of Demographic Characteristics Versus Demand of Participants for Cervical Cancer Screening in Tigray, Ethiopia, $2019(n=1,000)$

\begin{tabular}{|c|c|c|c|c|c|}
\hline & & \multicolumn{2}{|l|}{ Demand } & \multirow[t]{2}{*}{ Total (\%) } & \multirow[t]{2}{*}{$p$-value } \\
\hline & & Yes (\%) & No (\%) & & \\
\hline \multirow[t]{4}{*}{ Age-group, years } & $20-30$ & $76(36.5)$ & $132(63.5)$ & $208(20.8)$ & \multirow[t]{4}{*}{0.001} \\
\hline & $31-40$ & $259(5 \mathrm{I} .7)$ & $242(48.3)$ & $501(50.1)$ & \\
\hline & $4 I-50$ & II3 (53.I) & $100(46.9)$ & $213(2 \mid .3)$ & \\
\hline & $5 I-60$ & $32(41.0)$ & $46(59.0)$ & $78(7.8)$ & \\
\hline \multirow[t]{2}{*}{ Religion } & Orthodox & $462(49.0)$ & $480(5 \mathrm{I} .0)$ & $942(94.2)$ & \multirow[t]{2}{*}{0.008} \\
\hline & Muslim & $18(31.0)$ & 40 (7.69) & $58(5.8)$ & \\
\hline \multirow[t]{3}{*}{ Marital status } & Married & 332 (51.9) & $308(48.1)$ & $640(64.0)$ & \multirow[t]{3}{*}{0.632} \\
\hline & Divorced & $128(50.6)$ & $125(49.4)$ & $253(25.3)$ & \\
\hline & Unmarried & $60(56.1)$ & 47 (43.9) & $107(10.7)$ & \\
\hline \multirow[t]{4}{*}{ Education } & None & $70(3 \mid .2)$ & $154(68.8)$ & $224(22.4)$ & \multirow[t]{4}{*}{$<0.001$} \\
\hline & Primary & I $30(43.5)$ & $169(56.5)$ & $299(29.9)$ & \\
\hline & Secondary & $197(57.3)$ & I 47 (42.7) & $344(34.4)$ & \\
\hline & Tertiary & $83(62.4)$ & $50(37.6)$ & $133(13.3)$ & \\
\hline \multirow[t]{5}{*}{ Occupation } & Civil servant & $75(68.8)$ & $34(3 \mid .2)$ & $109(10.9)$ & \multirow[t]{5}{*}{$<0.001$} \\
\hline & Merchant & 88 (44.7) & $109(55.3)$ & 197 (19.7) & \\
\hline & Housewife & $209(52.4)$ & $190(47.6)$ & 399 (39.9) & \\
\hline & Daily work & $54(29.5)$ & $129(70.5)$ & $183(18.3)$ & \\
\hline & Privately employed & $54(48.2)$ & $58(51.8)$ & $112(1 \mathrm{I} .2)$ & \\
\hline
\end{tabular}


Table 2 Bivariate Analysis of Reproductive Health Variables Versus Demand for Cervical Cancer Screening in Tigray, Ethiopia, 2019 $(n=1,000)$

\begin{tabular}{|c|c|c|c|c|c|}
\hline & & \multicolumn{2}{|l|}{ Demand } & \multirow[t]{2}{*}{ Total (\%) } & \multirow[t]{2}{*}{$p$-value } \\
\hline & & Yes (\%) & No (\%) & & \\
\hline Contraceptive use & $\begin{array}{l}\text { Yes } \\
\text { No }\end{array}$ & $\begin{array}{l}285(51.4) \\
195(43.7)\end{array}$ & $\begin{array}{l}269(48.6) \\
251(56.3)\end{array}$ & $\begin{array}{l}554(55.4) \\
446(44.6)\end{array}$ & 0.015 \\
\hline Pregnancies had & $\begin{array}{l}\text { One to four } \\
\text { Five or more } \\
\text { None }\end{array}$ & $\begin{array}{l}370(48.4) \\
80(47.6) \\
30(44.8)\end{array}$ & $\begin{array}{l}395(51.6) \\
88(52.4) \\
37(55.2)\end{array}$ & $\begin{array}{l}765(76.5) \\
168(16.8) \\
67(6.7)\end{array}$ & 0.848 \\
\hline Number of children & $\begin{array}{l}\text { One to four } \\
\text { Five or more } \\
\text { None }\end{array}$ & $\begin{array}{l}380(48.4) \\
59(49.2) \\
41 \quad(43.2)\end{array}$ & $\begin{array}{l}405(51.6) \\
61(50.8) \\
54(56.8)\end{array}$ & $\begin{array}{l}785(78.5) \\
120(12.0) \\
95(9.5)\end{array}$ & 0.603 \\
\hline Abortions & $\begin{array}{l}\text { One or more } \\
\text { None }\end{array}$ & $\begin{array}{l}104(58.4) \\
376(45.7)\end{array}$ & $\begin{array}{l}74(41.6) \\
446(54.3)\end{array}$ & $\begin{array}{l}178(17.8) \\
822(82.2)\end{array}$ & 0.002 \\
\hline
\end{tabular}

294 (29.4\%)were knowledgeable, and of those, $258(87.8 \%)$ had demanded cervical cancer screening, significantly more than those who were less knowledgeable (222 [31.4\%; $p<0.001)$. In sum, $349 \quad(34.97 \%)$ had positive attitudes toward cervical cancer careening, of which 297 $(85.1 \%)$ had demand for cervical cancer screening $(p<0.001)$.

\section{Community-Level Variables}

Among the participants, $523(52.30 \%)$ were living in rural districts. Of the urban dwellers, 261 (54.7\%) had demand for cervical cancer screening. Mean family size of the clusters was $3.1-5.13$, with an overall mean of $4.02 \pm 0.49$. Communityawareness scores ranged 1.52-8.26 with a mean of 4.36 \pm 1.86 . The health professional:population ratios per thousand were $1.45-23.46$, with a mean of $5.67 \pm 4.18$. Population: health-institution ratios were $2,600-42,341$, with a mean of $15,651 \pm 9,546.76$. Literacy at the district level was $10.3 \%$ $100 \%$, with a mean of $72.63 \pm 29.25$.

\section{Demand for Cervical Cancer Screening}

Overall, those with a demand for cervical screening numbered 480 (48\%): 473 (47.3\%) expressed willingness during the interview to undertake cervical cancer screening, $207(20.7 \%)$ planned to get screened within the coming 6 months, and only $90(9.0 \%)$ had been screened for cervical cancer in their lifetime.

\section{Factors Associated with Demand for Cervical Cancer Screening}

Based on the bivariate analysis, variables with $p \leq 0.05$ were used in the multilevel multivariate analysis. Among the individual variables, age group, religion, educational status, occupation, contraceptive use, abortion, age at first sex, STI history, knowledge of cervical cancer, and attitudes toward cervical cancer screening showed significance.Among the community variables, type of district, mean family size, mean community awareness, ratio of households to health-extension workers, ratio of health professionals to population per thousand, and ratio of population to health institutions were significant. Other individual- and community-level variables did not attain significanceon Pearson's $\chi^{2}$.

\section{Multilevel Multivariate Analysis}

Measures of both association and variation were analyzed using individual- and community-level variables. Using the "xtmelogit" command, the null model (model I) showed that there was statistically significant variation in the odds of demand for cervical cancer screening among clusters. The intraclass correlation in the null model indicated that $18.9 \%$ of the total variance in women's demand for cervical cancer screening was attributable to differences among district clusters $(p<0.0001)$.

After adjustment for individual-level variables in model II, the intraclass correlation showed that $11.9 \%$ of the variation in demand for cervical cancer screening was because of differences among clusters. The proportional change in variance of this model showed that $42 \%$ of the variance in demand across clusters was explained by individual-level variables. After adjustment for both individual- and community-level variables in model III, 71.6\% 
Table 3 Bivariate Analysis of Cervical Cancer Risk Factors versus Demand for Cervical Cancer Screening in Tigray, Ethiopia, 2019 $(n=1,000)$

\begin{tabular}{|c|c|c|c|c|c|}
\hline & & \multicolumn{2}{|l|}{ Demand } & \multirow[t]{2}{*}{ Total (\%) } & \multirow[t]{2}{*}{$p$-value } \\
\hline & & Yes (\%) & No (\%) & & \\
\hline Age at first sex & $\begin{array}{l}\leq 20 \text { years } \\
\geq 21 \text { years }\end{array}$ & $\begin{array}{l}402(46.4) \\
78(58.6)\end{array}$ & $\begin{array}{l}465(53.6) \\
55(4 I .4)\end{array}$ & $\begin{array}{l}867(86.7) \\
133(13.3)\end{array}$ & 0.008 \\
\hline Lifetime sexual partner(s) & $\begin{array}{l}\text { One } \\
\text { Two or more }\end{array}$ & $\begin{array}{l}277(47.1) \\
203(49.27)\end{array}$ & $\begin{array}{l}311(52.9) \\
209(50.73)\end{array}$ & $\begin{array}{l}588(58.8) \\
4 I 2(4 \mid .2)\end{array}$ & 0.500 \\
\hline Smoking & $\begin{array}{l}\text { Yes } \\
\text { No }\end{array}$ & $\begin{array}{l}28(40.0) \\
452(48.6)\end{array}$ & $\begin{array}{l}42(60.0) \\
478(51.4)\end{array}$ & $\begin{array}{l}70(7.0) \\
930(93.0)\end{array}$ & 0.165 \\
\hline Alcohol use & $\begin{array}{l}\text { Always } \\
\text { Sometimes } \\
\text { Never }\end{array}$ & $\begin{array}{l}38(55.1) \\
299(49.1) \\
143(44.4)\end{array}$ & $\begin{array}{l}31(44.9) \\
310(50.9) \\
179(55.6)\end{array}$ & $\begin{array}{l}69(6.9) \\
609(60.9) \\
322(32.2)\end{array}$ & 0.188 \\
\hline Corticosteroid use & $\begin{array}{l}\text { Yes } \\
\text { No }\end{array}$ & $\begin{array}{l}47(56.6) \\
433(47.2)\end{array}$ & $\begin{array}{l}36(43.4) \\
484(52.8)\end{array}$ & $\begin{array}{l}83(8.3) \\
917(91.7)\end{array}$ & 0.100 \\
\hline History of sexually transmitted infection & $\begin{array}{l}\text { Yes } \\
\text { No }\end{array}$ & $\begin{array}{l}110(62.15) \\
370(44.96)\end{array}$ & $\begin{array}{l}67(37.8) \\
453(55.04)\end{array}$ & $\begin{array}{l}177(17.7) \\
823(82.3)\end{array}$ & 0 \\
\hline
\end{tabular}

of the proportional change in variance in the demand for cervical cancer screening across clusters was explained by both individual- and community-level variables. Finally, the variance-partition coefficient decreased from $18.9 \%$ in the null model to $6 \%$ in the final model (Table 4 ).

Compared to those aged $<30$ years, participants aged 31-40 years (AOR 2.33, 95\% CI $0.42-3.83$ ) and $41-50$ years (AOR 3.02, 95\% CI 1.64-5.55) were more likely to have demand for cervical cancer screening. Compared

Table 4 Distribution of Measures of Variation in Demand for Cervical Cancer Screening in Tigray, Ethiopia, $2019(n=1,000)$

\begin{tabular}{|l|l|l|l|}
\hline $\begin{array}{l}\text { Variability and } \\
\text { Model Test }\end{array}$ & $\begin{array}{l}\text { Model } \\
\text { I (null) }\end{array}$ & Model II & Model III \\
\hline Variance & 0.7709658 & 0.4467945 & 0.219282 \\
ICC & $0.189854 I$ & 0.1195705 & 0.0624886 \\
PCV (\%) & Reference & 0.42047429 & 0.71557493 \\
\hline Model selection & & & \\
LR & -640.36628 & -413.34727 & -406.35585 \\
AIC & $1,284.733$ & 864.6945 & 864.7117 \\
BIC & $1,294.548$ & 957.9419 & 992.3133 \\
\hline Model-fit diagnostics & \multicolumn{3}{|l}{} \\
VIF & Mean VIF & 1.71 \\
LROC & Area under ROC curve & 0.9039 \\
\hline
\end{tabular}

Abbreviations: AIC, Akaike information criterion; BIC, Bayesian information criterion; ICC, intraclass-correlation coefficient; LR, likelihood ratio; LROC, log of receiver-operating characteristic; PCV, proportional change in variance; VIF, variance-inflation factor. with orthodox Christians, Muslims were $67 \%$ less likely (AOR $0.33,95 \%$ CI $0.14-0.78$ ) to have demand for cervical cancer screening. Participants with secondary education (AOR 2.01, 95\% CI 1.19-3.39) and tertiary education (AOR 2.81, 95\% CI 1.43-5.51) were more likely to have a demand for cervical cancer screening than those who have no formal education.

Daily workers were $68 \%$ (AOR $0.32,95 \%$ CI 0.14 $0.69)$, less likely to have a demand for cervical cancer screening than civil servants. Participants with a history of STIs were 1.71 times (AOR 1.71, 95\% CI 1.05-2.79), more likely to have a demand for cervical cancer screening than their counterparts. Participants who were knowledgeable about cervical cancer were 9.21 times (AOR 9.21, 95\% CI 5.79-14.65) more likely to have a demand for cervical cancer screening than those who were less knowledgeable. In addition, those with a positive attitude toward cervical cancer screening were 8.32 times (AOR 8.32, 95\% CI 5.53-12.51) more likely to have a demand for cervical cancer screening than their counterparts.

Among the community-level variables, community awareness showed a significant association with demand. For every unit increase in mean community-awareness score, there was an increase in demand for cervical cancer screening of $25 \%$ (AOR $1.25,95 \%$ CI $1.05-1.48$ ). For each unit increase in the ratio of population to health institutions, there was a decrease in demand for cervical 
Table 5 Multilevel mutivariable Logistic Regression Analysis of Individual and Community Variable by Demand for Cervical Cancer Screening in Tigray, Ethiopia, $2019(n=1,000)$

\begin{tabular}{|c|c|c|c|c|c|}
\hline \multicolumn{2}{|l|}{ Individual } & \multicolumn{2}{|l|}{ Demand } & \multicolumn{2}{|l|}{ AOR $(95 \% \mathrm{Cl})$} \\
\hline & & \multirow{2}{*}{$\begin{array}{l}\text { Yes (\%) } \\
76(36.5) \\
259(51.7) \\
113(53.1) \\
32(41.0)\end{array}$} & \multirow{2}{*}{$\begin{array}{l}\text { No (\%) } \\
132(63.5) \\
242(48.3) \\
100(46.9) \\
46(59.0)\end{array}$} & \multirow{2}{*}{$\begin{array}{l}\text { Model II } \\
\text { I } \\
2.43(1.48,4.00)^{* * *} \\
3.10(1.69,5.70)^{* * *} \\
1.59(0.70,3.63)\end{array}$} & \multirow{2}{*}{$\begin{array}{l}\text { Model III } \\
\text { I } \\
2.33(0.42,3.83))^{* *} \\
3.02(I .64,5.55)^{* * *} \\
\text { I.53 }(0.67,3.47)\end{array}$} \\
\hline Age-group, years & $\begin{array}{l}20-30 \\
3 I-40 \\
4 I-50 \\
5 I-60\end{array}$ & & & & \\
\hline Religion & $\begin{array}{l}\text { Orthodox } \\
\text { Muslim }\end{array}$ & $\begin{array}{l}462(49.0) \\
18(31.0)\end{array}$ & $\begin{array}{l}480(51.0) \\
40(7.69)\end{array}$ & $\begin{array}{l}\mathrm{I} \\
0.36(0.15,0.83)^{*}\end{array}$ & $\begin{array}{l}\text { I } \\
0.33(0.14,0.78)^{*}\end{array}$ \\
\hline Education & $\begin{array}{l}\text { None } \\
\text { Primary } \\
\text { Secondary } \\
\text { Tertiary }\end{array}$ & $\begin{array}{l}70(31.2) \\
130(43.5) \\
197(57.3) \\
83(62.4)\end{array}$ & $\begin{array}{l}154(68.8) \\
169(56.5) \\
147(42.7) \\
50(37.6)\end{array}$ & $\begin{array}{l}\mathrm{I} \\
\mathrm{I} .43(0.84,2.4 \mathrm{I}) \\
2.07(\mathrm{I} .22,3.5 \mathrm{I}) \\
2.80(\mathrm{I} .42,5.52)\end{array}$ & $\begin{array}{l}\text { I } \\
\text { I.42 }(0.84,2.39) \\
2.0 \mathrm{I}(1.19,3.39)^{* *} \\
2.8 \mathrm{I}(\mathrm{I} .43,5.5 \mathrm{I})^{* *}\end{array}$ \\
\hline Occupation & $\begin{array}{l}\text { Civil servant } \\
\text { Merchant } \\
\text { Housewife } \\
\text { Daily work } \\
\text { Privately employed }\end{array}$ & $\begin{array}{l}75(68.8) \\
88(44.7) \\
209(52.4) \\
54(29.5) \\
54(48.2)\end{array}$ & $\begin{array}{l}34(31.2) \\
109(55.3) \\
190(47.6) \\
129(70.5) \\
58(51.8)\end{array}$ & $\begin{array}{l}\text { I } \\
0.55(0.27,1.11) \\
0.75(0.38,1.45) \\
0.29(0.13,0.63) * * \\
0.54(0.24,1.20)\end{array}$ & $\begin{array}{l}\text { I } \\
0.60(0.29,1.22) \\
0.77(0.39,1.49) \\
0.32(0.14,0.69) \\
0.58(0.26,1.29)\end{array}$ \\
\hline Contraceptive use & $\begin{array}{l}\text { Yes } \\
\text { No }\end{array}$ & $\begin{array}{l}285(51.4) \\
195(43.7)\end{array}$ & $\begin{array}{l}269(48.6) \\
25 I(56.3)\end{array}$ & $\begin{array}{l}1.35(0.90,2.00) \\
1\end{array}$ & $\begin{array}{l}1.27(0.85,1.89) \\
\text { I }\end{array}$ \\
\hline Abortion(s) & $\begin{array}{l}\text { One or more } \\
\text { None }\end{array}$ & $\begin{array}{l}104(58.4) \\
376(45.7)\end{array}$ & $\begin{array}{l}74(4 I .6) \\
446(54.3)\end{array}$ & $\begin{array}{l}1.48(0.92,2.38) \\
\text { I }\end{array}$ & $\begin{array}{l}1.38(0.86,2.23) \\
\text { I }\end{array}$ \\
\hline Age at first sex & $\begin{array}{l}\leq 20 \text { years } \\
\geq 21 \text { years }\end{array}$ & $\begin{array}{l}402(46.4) \\
78(58.6)\end{array}$ & $\begin{array}{l}465(53.6) \\
55(41.4)\end{array}$ & $1.10(0.63,1.93)$ & $\begin{array}{l}\text { I.II }(0.63,1.95) \\
\text { I }\end{array}$ \\
\hline History of sexually transmitted infection & $\begin{array}{l}\text { Yes } \\
\text { No }\end{array}$ & $\begin{array}{l}110(62.2) \\
370(44.9)\end{array}$ & $\begin{array}{l}67(37.8) \\
453(55)\end{array}$ & $\begin{array}{l}\mathrm{I} .80(\mathrm{I} . \mathrm{I} \mathrm{I}, 2.94)^{*} \\
\mathrm{I}\end{array}$ & $\begin{array}{l}1.7 \mid(1.05,2.79)^{*} \\
\text { । }\end{array}$ \\
\hline Knowledge of cervical cancer & $\begin{array}{l}\text { Knowledgeable } \\
\text { Less knowledgeable }\end{array}$ & $\begin{array}{l}258(87.7) \\
222(31.4)\end{array}$ & $\begin{array}{l}36(12.2) \\
484(68.5)\end{array}$ & $\begin{array}{l}9.7(6.13,15.33)^{* * *} \\
1\end{array}$ & $\begin{array}{l}9.2(5.79,14.7)^{* * *} \\
\text { । }\end{array}$ \\
\hline Attitude regarding cervical cancer & $\begin{array}{l}\text { SupportPositive } \\
\text { Lesspositive }\end{array}$ & $\begin{array}{l}297(85.1) \\
183(28.1)\end{array}$ & $\begin{array}{l}52(14.9) \\
468(71.9)\end{array}$ & $\begin{array}{l}8.7(5.79,13.09)^{* * *} \\
\text { । }\end{array}$ & $\begin{array}{l}8.3(5.53,12.5)^{* * *} \\
\text { । }\end{array}$ \\
\hline \multicolumn{6}{|l|}{ Community } \\
\hline Type of district & $\begin{array}{l}\text { Urban } \\
\text { Rural }\end{array}$ & & & & $\begin{array}{l}\mathrm{I} .04(0.59,1.82) \\
\mathrm{I}\end{array}$ \\
\hline \multicolumn{5}{|l|}{ Mean family size among clusters } & $1.16(0.67,2.01)$ \\
\hline \multicolumn{5}{|c|}{ Mean score of community awareness among clusters } & $1.25(1.05,1.48)^{* *}$ \\
\hline \multicolumn{5}{|c|}{ Ratio of households to HEW across clusters } & $0.99(0.99,1.00)$ \\
\hline \multicolumn{5}{|c|}{ Ratio of health professionals to population/I,000 across clusters } & $0.95(0.88,1.03)$ \\
\hline \multicolumn{5}{|c|}{ Ratio of population to health institutions across clusters } & $0.99(0.99,0.99)^{*}$ \\
\hline \multicolumn{5}{|c|}{ Literacy of zonal average across clusters } & $0.98(0.96,1.00)$ \\
\hline
\end{tabular}

Notes: ${ }^{*} p<0.05 ; * * p<0.01 ; * * * p<0.001$.

Abbreviation: HEW, health-extension worker.

cancer screening of $1 \%$ (AOR 0.99 , 95\% CI 0.99-0.99; Table 5). Demand for cervical cancer screening was inversely associated with the ratio of population to health institutions across clusters.

\section{Discussion}

Demand for cervical cancer screening was assessed based on willingness, plans to screen, and/or being screened. The demand for cervical cancer in the community is low 
compared to the government's plan for 2020. Women's demand for cervical cancer screening was subject to variations across the cluster districts. This could be due to better community awareness of cervical cancer and population:health institution difference across the community. Demand for cervical cancer screening was high among those aged $31-50$ years. Having a tertiary education, history of STIs, previous knowledge about cervical cancer, and positive attitude toward cervical cancer screening were variables significantly associated with demand for cervical screening.

The observed demand for cervical cancer screening in the community is higher than findings in Kenya, which were $11 \%{ }^{5}$ This might be because of bettercommunity penetration by health-extension workers in Ethiopia: the country has had a community health-extension program since 2003. Health-extension workers strengthen the health outcomes and coverage of essential services, mainly focusing on maternal- and child- health services in villages of Ethiopia. Regarding knowledge, only 294 (29.4\%) of the study participants had good knowledge. This is less than studies done in Nigeria (32.3\%) and Gambia (37.4\%). ${ }^{3,15}$ This could be because the study was conducted in mostly rural areas. Ethiopia started the cervical cancer screeninservice expansion and mobilization officially in 2015.

In this study, only $20.7 \%$ planned to get screened within the following 6 months and $9.0 \%$ had ever been screened for cervical cancer. This finding is less than the study in Burkina Faso $(63 \%)$ and greater than the study in Nigeria(3\%). ${ }^{3,4}$ Ethiopia introduced cervical cancer screening more recently than other east African countries. Participants aged 30 years and above showed demand for cervical cancer screening, similar to a study done in Lagos. ${ }^{5}$ One possible explanation could be that women aged 30 or more years have experienced reproductive-organ screening, which might enable them to use the chance for cervical cancer screening.

Muslim followers were less likely to have a demand for cervical cancer screening. Ethiopian families are generally male-dominated, and this might even be worse among the Muslim community and so could affect decisions on reproductive health issues, including cervical cancer screening. With increased education, the demand for cervical cancer screening also increased. This is supported by studies done in Kenya, the UK, Addis Ababa, and Latin American and Caribbean countries, wherein education was positively associated with cervical cancer screening. ${ }^{5,12,17,18}$ It is logical that educated individuals could be more inclined to promote their health status by being better informed.

Similarly, knowledge, community awareness, and positive attitudes toward cervical cancer screening were also strong predictors of demand for screening. This is similar to studies done in Nairobi, Gambia, Nigeria, the US, and Ethiopia that showed good knowledge on cervical cancer was a positive predictor of demand for screening. ${ }^{2,15-18} \mathrm{It}$ is also supported by studies done in the UK and Canada, which showed that good attitudes toward screening were a predictor of demand. ${ }^{12,13}$.The ratio of population to health institutions was a negative predictor of demand for screening. This makes sense: as the number of customers per institution increased, the chances of getting screened decreased.

In this study, civil servants had higher demand for cervical cancer screening than daily workers. This finding is supported by studies done in Kenya and Colombia, where cervical cancer screening was prevalent among employed women. ${ }^{6,10}$ Though cervical cancer screening is free in some governmental hospitals, it is expensive at private health institutions. This is why sustainable income among employed women matters in getting screened. Participants with a history of STIs showed demand for cervical cancer screening. It is reasonable that those exposed to STIs perceived themselves as needing more screening and were likely to get advice from health professionals about cervical cancer screening. One of the limitations of this study is that though mean multicollinearity was $<10$, most of the level two variables were aggregated from individual-level variables, which may have been correlated.

\section{Conclusion}

This study focused on demand for cervical cancer screening and associated factors. Based on the findings, close to half the participants showed demand. Age-groups 30-40 and 41-50 years, secondary and tertiary education, history of STIs, being knowledgeable, positive attitudes, and community awareness were positive predictors of demand. Being Muslims and a daily worker (level one variables) and population:health institution ratio (level two) were negative predictors of demand for cervical cancer screening.

It would be better if health professionals educated eligible women who visit their institutions about cervical cancer screening, and priority should be given those who have had STIs. It is recommended that policy-makers focus more on health-service accessibility 
and creation of demand for screening by planning healthpromotion strategies at institutional and community levels. Moreover, it is also recommended to enhance the education of the community, which correlates with demand for health-service utilization.

\section{Abbreviations}

AIC, Akaike information criterion; BIC, Bayesian information criterion; ICC, intracluster correlation; LR, likelihood ratio; LROC, log of receiver-operating characteristic curve; $\mathrm{PCV}$, proportional change in variance; STI, sexually transmitted infection;VIF, variance-inflation factor.

\section{Data-Sharing Statement}

Most of the relevant information is included in the manuscript, though raw data will be sent upon request.

\section{Ethical Approval and Consent to Participate}

Ethical approval was received from the institutional review board of the University of Gondar (registration OIV/P/RCS/05/308/2017). Participants were informed about the purpose of the study, that their participation was voluntary, their right of withdrawal, and the privacy and confidentiality of their information. Finally, written consent was checked before data collection.

\section{Acknowledgments}

We would like to acknowledge the University of Gondar, especially the Institute of Public Health, registrar, library, and secretary for creating an enabling environment and for their genuine and friendly facilitation of all researchrelated activities and legal issues. We would like also to extend our gratitude to the Tigray Regional Health Bureau and district health officers for their provision of support letters and guidance during data collection. Lastly, we express our heartfelt thanks to data collectors and participants for their genuine participation, information provision, and all their input in the development of this paper.

\section{Author Contributions}

All authors made substantial contributions to conception and design, acquisition of data, or analysis and interpretation of data, took part in drafting the article or revising it critically for important intellectual content, gave final approval to the version to be published, and agree to be accountable for all aspects of the work.

\section{Funding}

Since this study was in fulfillment of a dissertation, there was no registered fund from the home and hosting universities. Those organizations did not have any role from the conception of the paper until its completion.

\section{Disclosure}

The authors declare that they have no competing interests for this work.

\section{References}

1. Organization WH, Cancer IAfRo. Prevention of Cervical Cancer Through Screening Using Visual Inspection with Acetic Acid (VIA) and Treatment with Cryotherapy. A Demonstration Project in Six African Countries. Malawi, Madagascar, Nigeria, Uganda, the United Republic of Tanzania, and Zambia; 2009.

2. de Vries E, Arroyave I, Pardo C. Re-emergence of educational inequalities in cervical cancer mortality, Colombia 1998â€"2015. $J$ Cancer Policy. 2015;15:37-44.

3. Ouedraogo Y, Furlane G, Fruhauf T, et al. Expanding the single-visit approach for cervical cancer prevention: successes and lessons from Burkina Faso. Glob Health Sci Pract. 2018;6(2):288-298.

4. Balogun M, Odukoya O, Oyediran M, Ujomu P. Cervical cancer awareness and preventive practices: a challenge for female urban slum dwellers in Lagos, Nigeria. Afr J Reprod Health. 2012;16(1).

5. mwikali Mj. Factors Influencing Demand for Cervical Cancer Screening Services in Health Facilities in Kenya: A Case of Yatta Sub-County. Grey: university of nairobi; 2014.

6. Adeoye OO, Fawole O, Ajayi I, Nguku P. Cervical cancer knowledge, screening service utilization and predictors of precancerous cervical changes: a population based survey of sexually activewomen in Lagos, South Western Nigeria. OJPHI. 2014;6(1).

7. de Vriesa E, Arroyaveb I, Pardo C. Re-emergence of educational inequalities in cervical cancer mortality, Colombia 1998-2015. J Cancer Policy. 2018;15(2018):37-44. doi:10.1016/j.jcpo.2017. 12.007

8. Bermedo-Carrasco S, J N. P-S, Lepnurm R, Szafron M, Waldner C. Inequities in cervical cancer screening among Colombian women: a multilevel analysis of a nationwide survey. Int $J$ Cancer Epidemiol. 2015;39(2):229-236. doi:10.1016/j.canep.2015.01.011

9. Woltman KJ, Newbold KB. Immigrant women and cervical cancer screening uptake. Public Health. 2007;4(6):98.

10. Adeoye OO, Fawole O, Ajayi I, Nguku P. Cervical cancer knowledge, screening service utilization and predictors of precancerous cervical changes: a population based survey of sexually active women in Lagos, South Western Nigeria. Online J Public Health Inform. 2014;6(1).

11. Cham B. Knowledge, practice and acceptability of cervical cancer screening among midwives in the Gambia. Womens Health Sci J. 2018;2(3):000-123.

12. Ezem BU. Awareness and uptake of cervical cancer screening in Owerri, South-Eastern Nigeria. Ann Afr Med. 2007;6(3):94-98. doi:10.4103/1596-3519.55727

13. Belete N, Tsige Y, Mellie H. Willingness and acceptability of cervical cancer screening among women living with HIV/AIDS in Addis Ababa, Ethiopia: a cross sectional study. Gynecol Oncol Res Pract. 2015;2(1). doi:10.1186/s40661-015-0012-3

14. Labeit AM, Peinemann F, Dalby AR. Determinants of a GP visit and cervical cancer screening examination in Great Britain. PLoS One. 2017;12(4):4. doi:10.1371/journal.pone.0174363 
15. Chang SCH, Woo JST, Gorzalka BB, Brotto LA. A questionnaire study of cervical cancer screening beliefs and practices of chinese and caucasian mother-daughter pairs living in Canada. J Obstet Gynaecol Can. 2010;32(3):254-262. doi:10.1016/S1701-2163(16) 34452-8

16. Liebermann EJ, VanDevanter N, Hammer MJ, Fu MR. Social and cultural barriers to women's participation in pap smear screening programs in low- and middle-income Latin American and Caribbean Countries: an integrative review. J Transcult Nurs. 2018;29(6):591-602. doi:10.1177/1043659618755424

17. Twinomujuni CNF, Nuwaha F, Babirye JN. Understanding the low level of cervical cancer screening in masaka uganda using the ASE model: a community-based survey. PLoS One. 2015;10(6):6. doi:10.1371/journal.pone.0128498

18. Tiruneh FN, Chuang K-Y, Ntenda PAM, Chuang Y-C. Individuallevel and community-level determinants of cervical cancer screening among Kenyan women: a multilevel analysis of a Nationwide survey. BMC Womens Health. 2017;17(1). doi:10.1186/s12905-017-0469-9

19. Lofters AK, Moineddin R, Hwang SW, Glazier RH. Predictors of low cervical cancer screening among immigrant women in Ontario, Canada. BMC Womens Health. 2011;11(1):12. doi:10.1186/1472-6874-11-20

20. ICO. Human Papillomavirus and Related Cancers. Barcelona, Spain: Institut Català d'Oncologia; 2017.
21. Ethiopia FDRo. Population projection of ethiopia for all regions, at wereda level from 2014-2017. In: Agency CS, editor. Addis Ababa;2013.

22. Abel Gedefaw AA, G.A.T., The Prevalence of Precancerous Cervical Cancer Lesion among HIV-Infected Women in Southern Ethiopia. PLOS ONE. 2013;8(12):31-39.

23. Tadesse A. Knowledge, attitude and practice (KAP) towards screening for cervical cancer among Adama University female students. Adama, Ethiopia: Addis Ababa University; 2014.

24. Tadesse SK . Preventive Mechanisms and Treatment of Cervical Cancer in Ethiopia. Cervical Cancer. 2015;1:101. doi:10.4172/ 2475-3173.1000101

25. FDRE, MOH, health sector transformation plan, $2016-2020$. Ferderal democratic republic of Ethiopia, ministry of health, Addis Ababa 2015.

26. World Health Organization. Primary health care systems (PRIMASYS): case study from Georgia. Geneva: World Health Organization; 2017.

27. Yibeltal Assefa, community health extension program of Ethiopia, 2003-2018: successes and challenges toward universal coverage for primary healthcare services, Globalization and Health. 2019;15:24.

\section{Publish your work in this journal}

The International Journal of Women's Health is an international, peerreviewed open-access journal publishing original research, reports, editorials, reviews and commentaries on all aspects of women's healthcare including gynecology, obstetrics, and breast cancer. The manuscript management system is completely online and includes a very quick and fair peer-review system, which is all easy to use. Visit http://www.dovepress.com/testimonials.php to read real quotes from published authors. 